\title{
Racial-Ethnic Identity in Mid-Adolescence: Content and Change as Predictors of Academic Achievement
}

\author{
Inna Altschul and Daphna Oyserman \\ University of Michigan
}

\author{
Deborah Bybee \\ Michigan State University
}

\begin{abstract}
Three aspects of racial-ethnic identity (REI) — feeling connected to one's racial-ethnic group (Connectedness), being aware that others may not value the in-group (Awareness of Racism), and feeling that one's in-group is characterized by academic attainment (Embedded Achievement) — were hypothesized to promote academic achievement. Youth randomly selected from 3 low-income, urban schools ( $n=98$ African American, $n=41$ Latino) reported on their REI 4 times over 2 school years. Hierarchical linear modeling shows a small increase in REI and the predicted REI-grades relationship. Youth high in both REI Connectedness and Embedded Achievement attained better grade point average (GPA) at each point in time; youth high in REI Connectedness and Awareness of Racism at the beginning of 8th grade attained better GPA through 9th grade. Effects are not moderated by race-ethnicity.
\end{abstract}

Erikson (1968, p. 91) describes "the psychological aspect of adolescing" as an identity "crisis" in which one is to re-examine and reinterpret one's childhood self and begin to craft the adult one will become. This re-examination is to occur within a moratorium period in which various possible adult selves are tried on and discarded. This exploration can involve active engagement in and eventual creation of an identity, or the adoption of identities others provide for the self as one's own (Erikson, 1968). Erikson's notion of adolescence as a time of identity flux is well accepted, but problematic. First, does this mean that during adolescence identity really is unstable; that it changes so much that it cannot be used to predict outcomes? Second, does this mean that all aspects of identity undergo change, or is the identity "crisis" most relevant to those aspects of the self involved in establishing adult possible selves (e.g., those focused on the link between the self and school as a bridge to the adult world)?

In the current paper we examine the extent that one aspect of identity, racial-ethnic identity (REI), changes in mid-adolescence, and the extent that the relationship between REI and academic achievement is stable over time. We focus on understanding how

\footnotetext{
Funding for this study was provided by NIH Grant 58299 (Oyserman \& Bybee) and by the Michigan Prevention Research Training Grant (NIH Grant T32 MH63057-03). We thank our research team Kathy Terry, Tami Hart-Johnson, Carol Carlin, and Johnessa Dimicks, our interviewers, the teachers, parents, and students who made this research possible and Natalya Verbitsky for her invaluable assistance with HLM analyses.

Correspondence concerning this article should be addressed to Daphna Oyserman, 426 Thompson Ave., Institute for Social Research, University of Michigan, Ann Arbor, MI 48106-1248. Electronic mail may be sent to daphna.oyserman@umich.edu.
}

REI relates to school success and failure because doing well in school is an important life task in adolescence and school failure has important consequences both during adolescence and throughout the life course. During adolescence, school failure increases the risk of depression and delinquency (Dryfoos, 1997; Kasen, Cohen, \& Brook, 1998) and makes successful completion of other developmental tasks less likely (Sandler \& Chassin, 2002). In adulthood, it increases the risk of future unemployment, problems in parenting, and dampened mental health (e.g., Vander Stoep, Weiss, Kuo, Cheney, \& Cohen, 2003). We ask what content of REI is associated with better academic attainment or achievement, and whether this content is stable over time. These issues are important because other research has documented that low income and minority youth are at greatest risk of school failure (e.g., Ferguson, 2001; Gutman, Sameroff, \& Eccles, 2002; Leventhal \& Brooks-Gunn, 2004; McDermott, 1995; Orfield, Losen, Wald, \& Swanson, 2004), with risk higher for boys than for girls (Orfield et al., 2004). In addition, the transition to high school further elevates the risk of school failure for low-income and minority youth (Seidman, Aber, Allen, \& French, 1996).

How might minority racial-ethnic group identity influence academic achievement? As documented by the robust literature on stereotype threat and stereotype lift (Steele, 2004), simply being reminded of one's membership in a group that is stereotyped in terms of academic performance influences one's subsequent academic performance. This research suggests that REI may either promote or undermine

(C) 2006 by the Society for Research in Child Development, Inc. All rights reserved. 0009-3920/2006/7705-0004 
academic achievement depending on whether content of REI is positive or negative with regard to academics. When a positive stereotype exists (e.g., the "model minority" stereotype of Asian academic ability, Oyserman \& Sakamoto, 1997), then making the group membership salient is promotive of performance (Shih, Pittinsky, \& Ambady, 1999). When a negative stereotype exists, such is the case for working class (Croizet \& Claire, 1998), gender, and minority groups (Steele, 1997), making group membership salient is disruptive of performance.

\section{Operationalizing REI}

How might content of REI buffer youth from the negative impact of stereotypes? Indirect evidence suggests that REI ought to relate to better academic outcomes. Thus, parent racial or ethnic socialization is associated with more school efficacy and higher educational aspirations for African American youth (Bowman \& Howard, 1985), more ethnic knowledge, and a greater understanding of ethnic prejudice for Latino youths (Quintana \& Vera, 1999). What, then, is the content of REI that parents communicate to children? Based in the Oyserman, Gant, and Ager (1995) tripartite model, we focus on three aspects of REI: Connectedness, Awareness of Racism, and Embedded Achievement.

\section{REI Connectedness}

It is likely that a core part of REI is a positive sense of in-group belonging (Oyserman et al., 1995) or pride in the history, traditions, and ways of being of one's group (Quintana \& Segura-Herrera, 2003). Given the racialized nature of American society, youth are likely to know which racial or ethnic group they belong to (Bernal \& Knight, 1997) and, following social identity theory (e.g., Taijfel \& Turner, 1986), will be motivated to feel a positive sense of in-group belonging. According to Bernal and Knight's (1997) review, by middle childhood children will have developed a sense that racial-ethnic group membership is fixed, and have become aware of their own group membership and its social ramifications. A basic building block of this awareness is likely to be a positive connection to one's in-group or the feeling that racial-ethnic group membership is important to one's identity (e.g., Crocker, Luhtanen, Blaine, \& Broadnaz, 1994; Phinney, 1996; Sellers, Rowley, Chavous, Shelton, \& Smith, 1997). This has been termed REI Connectedness (Oyserman et al., 1995) To the extent that youth do not see their racial-ethnic group membership as part of who they are, they may not feel a particular need to act in ways congruent with in-group values or norms.

\section{REI Awareness of Racism}

Youth must also grapple with how out-group members view their group. This component of REI has been termed awareness of racism (Oyserman et al., 1995), awareness of others' prejudice (Quintana \& Segura-Herrera, 2003), or public regard (e.g., Crocker et al., 1994; Sellers et al., 1997). To the extent that racism and prejudice focus on negative stereotypes about academic interest, attainment, and achievement, REI Awareness of Racism may be helpful in buffering youth. Without REI Awareness of Racism, negative academic feedback might otherwise reduce the sustained effort to attain academic outcomes (see also Crocker \& Major, 1989). Developmental research suggests that awareness of others' negative view of one's racial-ethnic in-group and incorporation of this knowledge into REI occurs early (e.g., Quintana \& Segura-Herrera, 2003). Experimental evidence suggests that children act on racial stereotype information as young as age 6 , and seem to have internalized at least some aspects of this component of REI by early adolescence (Bigler, Averhart, \& Liben, 2003).

\section{REI Embedded Achievement}

REI Connectedness and REI Awareness of Racism, while important and commonly described as part of REI, do not specifically focus youth's attention on group values and norms with regard to school. Therefore, the tripartite model includes a third component of REI termed Embedded Achievement (Oyserman et al., 1995; Oyserman \& Harrison, 1998), the belief that achievement is an in-group identifier, a part of being a good in-group member, and the related sense that achievement of some in-group members helps other in-group members succeed. Because negative stereotypes about Black and Latino youth include low academic achievement, disengagement from school, and lack of academic ability (e.g., Oyserman et al., 1995), when academic achievement is not directly addressed within REI youth will be less able to recruit sufficient motivational attention to override these messages and stay focused on school success. By viewing achievement as part of being African American or Latino, identification with this goal is facilitated. The tripartite model proposes that especially when combined with REI Connectedness and REI Awareness of Racism, REI Embedded Achievement can provide a needed buffer against negative messages about the likelihood of success for poor and minority youths by 
incorporating school and achievement as in-group defining characteristics (Oyserman et al., 1995).

\section{REI and Academic Outcomes}

In a number of studies, Oyserman and her colleagues have examined the effectiveness of this tripartite model of REI operationalized as Connectedness, Awareness of Racism, and Embedded Achievement to predict academic outcomes (engagement, involvement, effort, grades) among African American youth. With regard to persistence on academic tasks Oyserman et al. (1995) found that when race was made salient, academic persistence declined except among youth high in all three REI components - Connectedness, Awareness of Racism, and Embedded Achievement. For these youth, persistence did not decline, providing clear evidence of the buffering effect of REI.

In another study focused on academic efficacy, fall REI significantly predicted spring academic efficacy even when controlling for fall grades and fall academic efficacy (Oyserman, Harrison, \& Bybee, 2001). In a third study focused on a school grades, school involvement and academically oriented possible selves, concern about school increased over time among youth high in all three REI components even when controlling for fall grades and concern about school (Oyserman, Bybee, \& Terry, 2003). In this study REI Connectedness predicted improved grades, increased study time, and more strategies to attain academic possible selves for boys even when controlling for fall grades. REI Embedded Achievement predicted improved grades for girls.

Oyserman et al. (1995) proposed that REI may be gendered in its consequences, with REI and gender identity providing complementary self-schemas, or organizing frameworks (Oyserman et al., 2001, 2003). Because gender- and racial-ethnic socialization both deal with connection, relationality, and family focus on the one hand, and independence, autonomy, and achievement on the other hand, components of REI can complement gender-identity. On average, girls are higher in relationality than boys (Cross \& Madson, 1997; Markus \& Oyserman, 1989); therefore they may particularly benefit from a sense of achievement as important to their in-group-REI Embedded Achievement. Conversely, boys, who are generally socialized to become autonomous and achieve, may particularly benefit from the connectedness component of REI as an alternative way of valuing connections with important others (e.g., Oyserman et al., 1995).

Although prior research has not explicitly compared African American and Latino youth on consequences of REI, it seems reasonable to expect that the three components of REI will have similar impact on academic achievement for African American and Latino youth. Prior research among Latino children (e.g., Bernal, Knight, Garza, Ocampo, \& Cota, 1990; Quintana, 1998) and African American college students (e.g., Sellers et al., 1997) has focused on sense of Connection and Awareness of Racism, indicating the relevance of these components of REI to both groups. With regard to REI Embedded Achievement, the need to incorporate school as part of racial-ethnic in-group identity should be universal (e.g., Oyserman, Kemmelmeier, Fryberg, Brosh, \& Hart-Johnson, 2003; Oyserman, Brickman, \& Rhodes, in press).

\section{Stability and Change in REI During Mid-Adolescence}

While the previously cited studies provide evidence that REI is likely to have developed by mid-adolescence and may be gendered in its impact, a separate question arises about contextually and developmentally determined change and stability in mid-adolescent REI. A number of models have posited that REI shifts over time in response to features of the social context (e.g., Cross, 1991; Oyserman, Kemmelmeier, et al., 2003); individuals are thought to cycle between being aschematic and schematic for race-ethnicity depending on the context. When context makes awareness of being a member of one's racial-ethnic ingroup imperative, individuals are likely to be schematic for race-ethnicity - that is, to define the self in terms of race-ethnicity. However, content of REI is likely to vary as context changes. Individuals may focus on the in-group only, on out-group racism and the need to overcome it, or on one's connection as a minority person with larger society more generally depending on contextual-environmental cues. These shifts have been demonstrated across high school; 9th graders were significantly more likely to be raceethnicity aschematic than 12th graders (Oyserman, Kemmelmeier, et al., 2003).

In the current paper we focus on early adolescence and the transition from middle to high school, from smaller homogeneous to larger, more heterogeneous high schools. This shift has been termed a consciousness-raising experience (French, Seidman, Allen, \& Aber, 2000). In homogeneous middle school contexts, race-ethnicity and income levels are more likely to be similar across students; therefore, students feel average and these characteristics do not appear to be self-defining (Steinitz \& Solomon, 1986). Heterogeneous high schools make both social class and racial-ethnic groups more salient and, in schools with tracking, tracking may provide labels for these 
groups with implications for one's group's relative standing and likely success.

Without the compass provided by an REI that makes clear that school is still relevant to one's future, youth may be likely to simply incorporate these negative future images into their emerging identity. But is REI stable enough by mid-adolescence to serve this compass function? The notion that REI changes during adolescence fits squarely with Erikson's (1968) model of adolescence as a time of identity exploration. Part of the identity work in adolescence should be a re-assessment of one's stance with regard to one's racial-ethnic group-how connected does one feel to this group, to what extent is this group valued or devalued in larger society, and how do in-group members value engagement with schooling. Indeed, there is some evidence that Embedded Achievement may not be stable; while in elementary school, Latino and African American boys perceive school success as an in-group characteristic, by early adolescence they no longer do (Graham, 2001); and they are more likely to assume that low achievers are male, Latino and African American (Hudley \& Graham, 2001).

\section{Hypotheses}

Following the literature, we hypothesized that in mid-adolescence REI Connectedness, Awareness of Racism, and Embedded Achievement would be sufficiently stable to predict academic attainment both at each point in time and over time and that the effect of REI would be consistent for both African American and Latino youths but may be gendered - with Connectedness being more important for boys and Embedded Achievement being more central for girls. To set the stage, we first examined change in each REI component over time.

\section{Method}

\section{Sample}

Participants were 139 eighth graders (98 African American and 41 Latino) at three low-income (67.3\% of students received free-reduced lunch), urban Detroit middle schools. Students were selected for participation at random such that half of the students in each eighth-grade home-room were eligible for participation. Data from 21 White students were excluded from analyses. The racial composition of this sample reflects the racial composition of the schools. Census tract $(n=105)$ data reaffirmed student's low socioeconomic status; $54.1 \%$ of households in the tracts where students lived were below the poverty line, and only $40 \%$ of adults were employed.

\section{Procedures}

Data are from the randomized control group of a preventive intervention trial (NIMH Grant R01 MH 58299, Oyserman \& Bybee, for details see Oyserman, Bybee, \& Terry, 2006). Before the first survey we mailed a letter to each student's home explaining the study and requesting parent or guardian consent for student participation. We then made personal contact (face-to-face or by telephone) to explain the project and request signed parental consent for tracking, data collection, and records release. This combined communication approach resulted in a 94.3\% permission rate, insuring that conclusions are generalizable to the population.

Grade records were obtained directly from the school or the district if student records were no longer at the school. REI data were collected at four points in time: fall eighth grade (September); spring eighth grade (April-May); fall ninth grade (September); and spring ninth grade (April-May). In eighth grade, questionnaires were self-administered in class during a single class period. Students not in school when the questionnaire was administered were looked for at school during the week and, if not found, visited at home for a Structured Interview to fill out the questionnaire. By ninth grade, students had transitioned from 3 to over 30 school sites. This made classroom-based administration impossible; therefore, ninth-grade youth data were collected following the eighth-grade at-home protocol.

\section{Measures}

REI. The three components of REI-Connectedness, Awareness of Racism, and Embedded Achievement-were assessed with 4-item, 5-point Likert response scale $(1=$ strongly disagree, $2=$ disagree, $3=$ neither agree nor disagree, $4=$ agree, $5=$ strongly agree) measures. Alpha reliability, mean, and standard deviation for Connectedness, Awareness of Obstacles-Racism, and Embedded Achievement at each wave and for each racial-ethnic group are presented in Table 1. Although the REI component scales are brief assessments, they were adequately reliable: for Connectedness (sample item: "I feel part of the Black community"), mean cross-wave $\alpha$ reliability $=.78$, $M=4.15, S D=.70$; for Awareness of Racism (sample item: "Because I am Black, others may have negative expectations of $\mathrm{me}^{\prime \prime}$ ), cross-wave $\alpha=.81, M=3.75$ $S D=.71$; for Embedded Achievement (sample item: 
Table 1

REI Connectedness, Embedded Achievement, and Awareness of Racism: Descriptive Statistics by Racial-Ethnic Group at Each Point in Time

\begin{tabular}{|c|c|c|c|c|c|c|c|c|c|}
\hline \multirow[b]{2}{*}{ REI component } & \multicolumn{3}{|c|}{ Connectedness } & \multicolumn{3}{|c|}{ Embedded Achievement } & \multicolumn{3}{|c|}{ Awareness of Racism } \\
\hline & $M$ & $S D$ & $\alpha$ & $M$ & $S D$ & $\alpha$ & $M$ & $S D$ & $\alpha$ \\
\hline \multicolumn{10}{|l|}{ Full sample $(n=139)$} \\
\hline Average over time & 4.15 & 0.70 & .78 & 3.75 & .71 & .81 & 3.40 & .81 & .65 \\
\hline Fall eighth grade & 3.96 & 0.85 & .78 & 3.62 & .84 & .69 & 3.24 & .84 & .55 \\
\hline Spring eighth grade & 4.08 & 0.84 & .83 & 3.69 & .76 & .66 & 3.38 & .83 & .62 \\
\hline Fall ninth grade & 4.33 & 0.51 & .66 & 3.86 & .65 & .62 & 3.51 & .77 & .64 \\
\hline Spring ninth grade & 4.20 & 0.57 & .75 & 3.78 & .68 & .67 & 3.45 & .83 & .76 \\
\hline \multicolumn{10}{|c|}{ African American youth $(n=98)$} \\
\hline Average over time & 4.24 & 0.66 & .78 & 3.83 & .70 & .62 & 3.56 & .79 & .60 \\
\hline Fall eighth grade & 4.03 & 0.74 & .74 & 3.71 & .77 & .67 & 3.36 & .82 & .54 \\
\hline Spring eighth grade & 4.20 & 0.78 & .86 & 3.78 & .74 & .62 & 3.60 & .74 & .51 \\
\hline Fall ninth grade & 4.40 & 0.48 & .66 & 3.90 & .64 & .57 & 3.66 & .71 & .53 \\
\hline Spring ninth grade & 4.29 & 0.53 & .72 & 3.87 & .64 & .60 & 3.57 & .86 & .77 \\
\hline \multicolumn{10}{|l|}{ Latino youth $(n=41)$} \\
\hline Average over time & 3.92 & 0.71 & .78 & 3.56 & .70 & .75 & 3.01 & .74 & .68 \\
\hline Fall eighth grade & 3.76 & 1.1 & .88 & 3.38 & .99 & .73 & 2.88 & .83 & .56 \\
\hline Spring eighth grade & 3.75 & 0.92 & .74 & 3.47 & .77 & .76 & 2.83 & .81 & .68 \\
\hline Fall ninth grade & 4.12 & 0.52 & .59 & 3.75 & .67 & .74 & 3.13 & .80 & .76 \\
\hline Spring ninth grade & 3.95 & 0.61 & .81 & 3.55 & .72 & .76 & 3.13 & .67 & .66 \\
\hline
\end{tabular}

Note. REI $=$ racial-ethnic identity.

"It is important for my family and the Black community that I succeed in school"), cross-wave $\alpha=.65$, $M=3.40, S D=.81$. Before answering these questions, youth were asked their main racial-ethnic group and were instructed to respond to the REI questions in terms of that group. The sample items were filled in as would be typical for African American students. Reliability is similar to that found in previous studies with the same measures: .62-.74 (Oyserman et al., 2001), .71-.79 (Fast Track, http://www.fasttrackproject.org/techrept/e/eio/ eio9tech.pdf), and .58-.74 (Oyserman, Bybee, et al., 2003). Only a small portion of responses across the four data points $(7.2 \%)$ were missing; to maintain generalizability, these were estimated from the full set of available data, using maximum likelihood methods (Schafer \& Graham, 2002) before hierarchical linear modeling (HLM), so that the full sample is used in all analyses. For analyses employing REI measures as covariates, scores were centered on the neutral scale midpoint $(3=$ neither agree nor disagree).

Core academic grade point average (GPA). Grades for core academic classes (English, math, history, and science) were obtained for all marking periods in the eighth and ninth grades. In the eighth-grade quarter grading periods ended in November, January, April, and June, while in the ninth-grade semester grading periods ended in January and June. The small por- tion of missing responses $(11.5 \%$ across the six data points) was estimated using maximum likelihood methods, enabling analysis of the full sample in order to optimize generalizability.

\section{Results}

\section{Analysis Plan}

Our analyses focus on our two main questions about REI Connectedness, Awareness of Racism, and Embedded Achievement. Does REI change systematically over time and relate to grades at each point in time and over time? And, are these effects consistent across race-ethnicity (and gender)? To answer these questions we first examined change in REI Connectedness, Awareness of Racism, and Embedded Achievement and grades, and then examined the association of these variables within and across time. We used HLM following procedures outlined by Raudenbush and Bryk (2002). HLM is well suited for analyses of longitudinal data as it accounts for the nesting of repeated measures within individuals. At level 1, individual trajectories of change are estimated as a function of time and time-varying covariates; at level 2, slope and intercept coefficients are modeled as a function of time-invariant (raceethnicity and gender) factors. 
Table 2

HLM Parameter Estimates for REI Connectedness, Embedded Achievement, and Awareness of Racism Over Time

\begin{tabular}{|c|c|c|c|c|c|c|}
\hline \multirow[b]{2}{*}{ Parameter estimates } & \multicolumn{2}{|c|}{ Connectedness } & \multicolumn{2}{|c|}{$\begin{array}{c}\text { Embedded } \\
\text { Achievement }\end{array}$} & \multicolumn{2}{|c|}{ Awareness of Racism } \\
\hline & Estimate & $p$ & Estimate & $p$ & Estimate & $p$ \\
\hline \multicolumn{7}{|l|}{ For intercept $\left(B_{0}\right)$} \\
\hline Constant $\left(G_{00}\right)$ & 4.14 & .001 & 3.76 & .001 & 3.48 & .001 \\
\hline Race-ethnicity (Latino) $\left(G_{01}\right)$ & -0.34 & .001 & -0.28 & .01 & -0.55 & .001 \\
\hline Random error $^{\mathrm{a}}\left(U_{0}\right)$ & 0.57 & .001 & 0.59 & .001 & 0.51 & .001 \\
\hline \multicolumn{7}{|l|}{ For slope $\left(B_{1}\right)$} \\
\hline Change (per month) $\left(G_{10}\right)$ & 0.010 & .001 & 0.0061 & .05 & 0.0071 & .05 \\
\hline Random error $^{\mathrm{a}}\left(U_{1}\right)$ & 0.022 & .001 & 0.020 & .001 & 0.021 & .01 \\
\hline
\end{tabular}

Note. $\mathrm{HLM}=$ hierarchical linear modeling; REI = racial-ethnic identity.

${ }^{\text {a }}$ Reported as standard deviation.

REI Connectedness, Embedded Achievement, Awareness of Racism, and GPA Trajectories

To examine whether REI Connectedness, Awareness of Racism, and Embedded Achievement change over time we developed HLM models for each of the three REI components over the 2-year study period. We focused on identifying time-related change in REI; therefore, we first developed models to describe each outcome variable with respect to time and then added race-ethnicity and gender covariates. Slope and intercept were allowed to vary independently. Nonlinear time terms were tested to allow for a potential nonlinear relationship with time, but they were not found to be significant. We used a similar strategy to model the GPA trajectory so as to establish a baseline (Model 1) with which we could compare models in which REI is used to predict GPA (Models 2 and 3). Equations for all three models appear in Appendix A.

Trajectory of REI Connectedness over time. REI Connectedness was linearly associated with time, showing a slight increase over the course of the 2year follow-up (.22 on the 5-point scale, $B_{1}=.01$ per month over 22 months). There was no effect of gender on fall eighth-grade Connectedness or on change in Connectedness over time. A significant effect for race-ethnicity was found for fall eighth-grade Connectedness, but not for change in Connectedness over time. African American students (estimated $M=4.14)$ were significantly higher in REI Connectedness (by .34) than Latino students (estimated $M=3.80$ ), and the size of this difference remained constant across time. The first block of Table 2 presents the parameters describing this relationship, with African American students as the reference. Between-student random errors were highly signif- icant, indicating variation between students in REI Connectedness both in the fall of eighth grade (intercept) and in change over time (slope).

Trajectory of Embedded Achievement over time. REI Embedded Achievement was linearly associated with time, showing a slight increase over the course of the 2-year follow-up (.13 on the 5-point scale, $B_{1}=.0061$ per month over 22 months). No effect of gender was found for either fall eighth-grade Embedded Achievement or change over time in Embedded Achievement. A significant effect for race-ethnicity was found for fall eighth-grade Embedded Achievement, but not for change in Embedded Achievement over time. African American students (estimated $M=3.76$ ) were significantly higher in REI Embedded Achievement (by .28) than Latino students (estimated $M=3.48$ ), and the size of this difference remained constant across time. The second block of Table 2 presents the parameters describing this relationship, with African American students as the reference. Between-student random errors were highly significant, indicating variation between students in REI Embedded Achievement both in the fall of eighth grade (intercept) and in change over time (slope).

Trajectory of Awareness of Racism over time. REI Awareness of Racism was linearly associated with time, showing a slight increase over the course of the 2-year follow-up (.16 on the 5-point scale, $B_{1}=.0071$ per month over 22 months). There was no effect of gender on fall eighth-grade Awareness of Racism or on change over time in Awareness of Racism. A significant effect for race-ethnicity was found for fall eighth-grade Awareness of Racism, but not for change in Awareness of Racism over time. African American students (estimated $M=3.48$ ) were significantly higher in REI Awareness of Racism (by .55) than Latino students (estimated $M=2.93$ ), and this 
Table 3

HLM Parameter Estimates for GPA Over Time

\begin{tabular}{|c|c|c|c|c|c|c|}
\hline \multirow[b]{2}{*}{ Parameter estimates } & \multicolumn{2}{|c|}{ Model 1} & \multicolumn{2}{|c|}{ Model 2} & \multicolumn{2}{|c|}{ Model 3} \\
\hline & Estimate & $p$ & Estimate & $p$ & Estimate & $p$ \\
\hline \multicolumn{7}{|l|}{ For intercept $\left(B_{0}\right)$} \\
\hline Constant $\left(G_{00}\right)$ & 2.42 & .001 & 2.36 & .001 & 2.34 & .001 \\
\hline Race-ethnicity (Latino) $\left(G_{01}\right)$ & -0.66 & .001 & -0.63 & .001 & -0.63 & .001 \\
\hline Gender (male) $\left(G_{02}\right)$ & -0.59 & .001 & -0.62 & .001 & -0.64 & .001 \\
\hline Race-ethnicity $\times$ Gender interaction (Latino and male) $\left(G_{03}\right)$ & 0.62 & .03 & 0.68 & .02 & 0.62 & .03 \\
\hline Fall eighth-grade Connectedness $\left(G_{04}\right)$ & & & & & 0.28 & .01 \\
\hline Fall eighth-grade Awareness of Racism $\left(G_{05}\right)$ & & & & & -0.077 & .37 \\
\hline \multicolumn{7}{|l|}{ Interaction fall eighth-grade Connectedness by } \\
\hline Fall eighth-grade Awareness of Racism $\left(G_{06}\right)$ & & & & & 0.26 & .02 \\
\hline Random error ${ }^{\mathrm{a}}\left(U_{0}\right)$ & 0.73 & .001 & 0.73 & .001 & 0.69 & .001 \\
\hline \multicolumn{7}{|l|}{ For slope $\left(B_{1}\right)$} \\
\hline Change (per month) $\left(G_{10}\right)$ & -0.028 & .001 & -0.028 & .001 & -0.028 & .001 \\
\hline \multicolumn{7}{|l|}{ Time-varying covariates } \\
\hline Connectedness $\left(B_{2}\right)$ & & & -0.053 & .39 & & \\
\hline Embedded achievement $\left(B_{3}\right)$ & & & -0.26 & .001 & & \\
\hline Awareness of Racism $\left(B_{4}\right)$ & & & 0.19 & .03 & & \\
\hline Connectedness by embedded achievement $\left(B_{5}\right)$ & & & 0.27 & .001 & & \\
\hline Random error ${ }^{\mathrm{a}}\left(U_{1}\right)$ & 0.036 & .001 & 0.035 & .001 & 0.036 & .001 \\
\hline
\end{tabular}

Note. HLM = hierarchical linear modeling; REI = racial-ethnic identity; GPA = grade point average. Model 1 is a simple model of GPA over time with no effects of REI; Model 2 shows the time-varying association of REI with GPA; Model 3 represents the effect of initial REI on GPA.

${ }^{\mathrm{a}}$ Reported as standard deviation.

difference remained constant across time. The final block of Table 2 presents the parameters describing this relationship with African American students as the reference. Between-student random errors were highly significant, indicating variation between students in REI Awareness of Racism in both fall of eighth-grade level intercept and in rate and direction of change over time (slope).

Trajectory of core GPA over time (Model 1). Core grades were linearly associated with time, showing significant decline over the course of the 2-year follow-up (.62 of a grade point, $B_{1}=-.028$ per month over 22 months). Gender and the interaction of gender and race-ethnicity were both associated with grades in the fall of eighth grade such that African American girls had significantly better grades (estimated $M=2.42$ ) than African American boys (estimated $M=1.83$ ), Latina girls (estimated $M=1.76$ ), and Latino boys (estimated $M=1.79$ ). These gendered raceethnicity differences remained constant across time. The first panel of Table 3 presents the parameters describing these relationships, with African American female students as the reference. Between-student random errors were highly significant, indicating variation between students in grades both in the fall of eighth grade and in rate of change over time.
Relationship Between REI Connectedness, Embedded Achievement, and Awareness of Racism and GPA Over Time

To examine whether REI Connectedness, Awareness of Racism, and Embedded Achievement are related to GPA over time, we used two approaches. First, we modeled the repeating association of REI with GPA across time for each student (Model 2) such that both REI and GPA were time-varying, with REI measured 2 months before GPA at each time point. Second, we used REI assessed in the fall of eighth grade to predict GPA trajectories across eighth and ninth grades (Model 3). Model 2 describes the association of REI and GPA at repeated points in time and allows us to examine proximal associations - what is the relationship between REI and GPA, as both vary across time? Model 3 focuses on the relationship of REI at the beginning of eighth grade with GPA trajectories that span the subsequent 2 years and allows us to answer the question: which components of REI, measured at the beginning of eighth grade, can predict the GPA trajectory across the 2-year study period?

In both Models 2 and 3, we began with the simple model of GPA over time (Model 1), then added REI 
main effects, and then the two- and three-way REI interaction effects, retaining interaction effects that were significant, along with the relevant lower order effects. In both Models 2 and 3, we insured stability of the final model built in this way by comparing the final model to the model that would be obtained by starting with all possible individual-level interaction effects and quadratic terms and removing stepwise the nonsignificant terms, starting with the most complex interactions (e.g., the quadratic of Connectedness $\times$ Awareness of Racism) and moving to the least complex (e.g., linear two-way interactions). This stepwise removal process allowed any potential nonlinear interactions to emerge. Both methods yielded the same results, confirming the stability of the final models. Only significant terms $(p \leq .05)$ are presented in the results below. The full (untrimmed) models appear in Appendix A.

Association of time-varying REI and GPA across time (Model 2). In examining the association of time-varying REI and GPA across the four time points, we found a main effect of REI Awareness of Racism and interaction effects of REI Embedded Achievement and REI Connectedness. Time-varying REI Connectedness, Embedded Achievement, and Awareness of Racism did not significantly interact with time in predicting GPA, suggesting that the effects of REI on GPA did not change systematically over time. And, although gendered effects of REI on grades were hypothesized, in this sample, the effects of REI were not significantly modified by gender. The second panel of Table 3 shows the significant effects in this model. As in Model 1, fall eighth-grade GPA differs significantly by gender and race-ethnicity. With regard to REI Awareness of Racism, at each assessment point youth high in Awareness of Racism were higher in GPA (with grades .19 GPA point higher for each point increase in REI Awareness of Racism). With regard to REI Embedded Achievement, a main effect was modified by an Embedded Achievement by Connectedness interaction effect, such that when youth were high in both REI Embedded Achievement and REI Connectedness, their GPAs were higher; this effect is presented graphically in Figure 1 (with REI Awareness of Racism held constant at the mean). For ease of interpretation, we plot REI Embedded Achievement and Connectedness scores at the 10th, 50th, and 90th percentiles, with percentiles reflecting the REI distributions across all time points and all four racial-ethnic and gender groups. We present the effect of the Embedded Achievement and Connectedness interaction on GPA applied to each gendered racial-ethnic group (Figure 1a). Although the effects of being high in both Embedded Achievement and Connectedness are constant across these groups, attained grades reflect differences in fall eighth-grade GPA between the four gender by race-ethnicity groups similar to those identified in Model 1. Likewise, the effects of the Embedded Achievement and Connectedness interaction remain constant across time; however, attained grades at the end of ninth grade reflect the overall decline in grades that occurs over time. To provide a representation of this shift, Figure 2 shows the estimated effects of this interaction on GPA at the beginning of eighth grade and again at the end of ninth grade (using as an example African American girls). Figure 2 can be used to understand shift over time. Grades and REI change linearly with time; therefore the relative modeled relationship of REI and GPA is the same at each point in time. Even as the absolute level of GPA and of REI shifts-downward for GPA and slightly upward for REI.

Effect of initial REI on GPA across time (Model 3). The significant interaction effect of fall eighth-grade Connectedness and Awareness of Racism on the level of GPA across eighth and ninth grades is shown in Figure 3. The third panel of Table 3 presents the parameters describing these relationships between fall eighth-grade REI and GPA across time. The interaction can be understood from two perspectives. First, at average levels of fall eighth-grade REI Awareness of Racism, fall eighth-grade REI Connectedness had a positive impact on the average level of GPA across eighth and ninth grades. Youth who are one point higher in fall eighth grade on REI Connectedness had GPAs that were .28 of a grade point higher across time. Second, fall eighth-grade REI Connectedness interacted with fall eighth-grade REI Awareness of Racism to also influence the intercept of the GPA trajectory. Thus, youths who were high in both Connectedness and Awareness of Racism at the beginning of eighth grade had higher GPAs across the 2-year study period, with higher levels of REI Awareness of Racism enhancing the positive effects of high REI Connectedness. The interactive effects of REI Connectedness and Awareness of Racism were related to the overall level of GPA across the 2 years (intercept). However, fall eighth-grade levels of REI were not related to extent of change in GPA across the 2-year time period (slope).

\section{Discussion}

We asked whether content of REI, operationalized as REI Connectedness, REI Awareness of Racism, and REI Embedded Achievement, is stable enough in mid-adolescence to buffer and sustain academic 
(a)

African American Girls

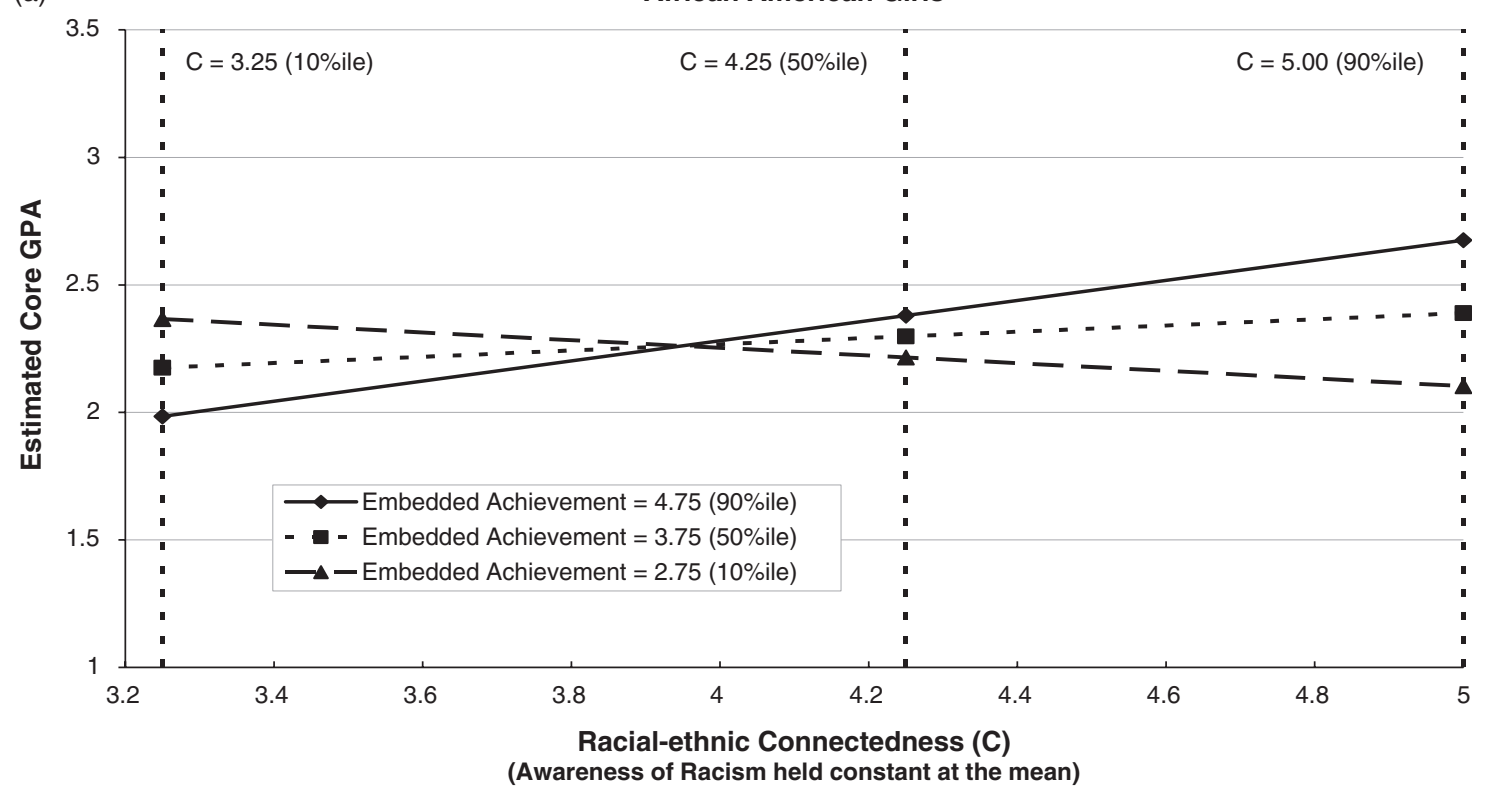

Note: Percentiles used reflect the REI distributions across all four time points and all four racial-ethnic and gender groups

(b)

African American Boys

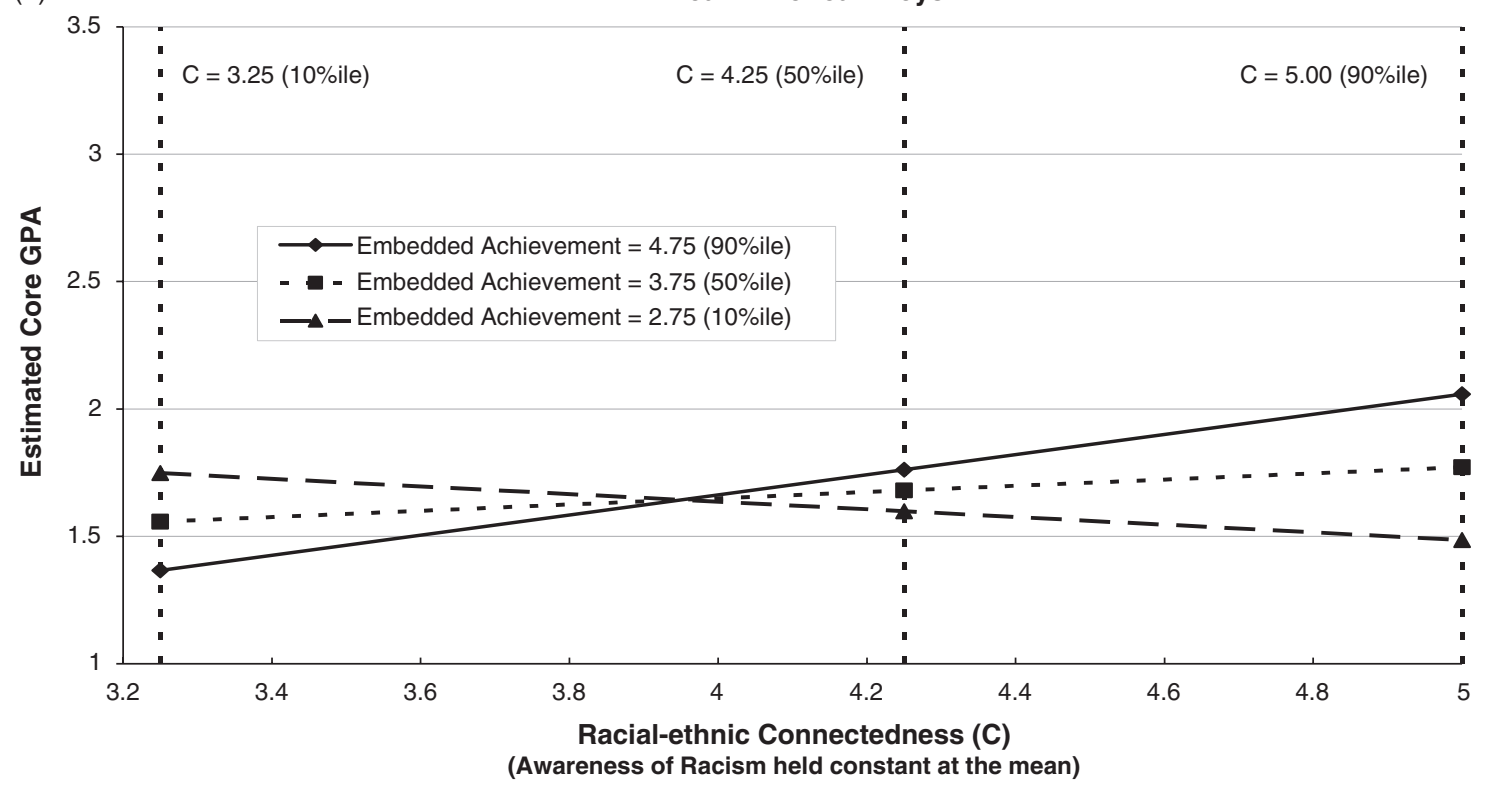

Note: Percentiles used reflect the REI distributions across all four time points and all four racial-ethnic and gender groups

Figure 1. Interactive effects of time-varying racial-ethnic identity (REI) Connectedness and Embedded Achievement on core grade point average for each gendered racial-ethnic group. Note. Percentiles used reflect the REI distributions across all four time points and all four racial-ethnic and gender groups.

achievement among low-income African American and Latino youth and, if so, whether effects are gendered. On the one hand, change in REI and especially REI Embedded Achievement could be expected. Adolescence is a time of identity flux. We followed youth during the transition from middle to high school, which is associated with drop in grades and connection to school. These changes may destabilize REI, especially REI Embedded Achievement (see French et al., 2000). On the other hand, developmental research suggests that at least two components of REI, Connectedness and Awareness of Racism, have already developed before mid-adolescence (e.g., Bernal \& Knight, 1997; Quintana, 1998). 
(a)

Latina Girls

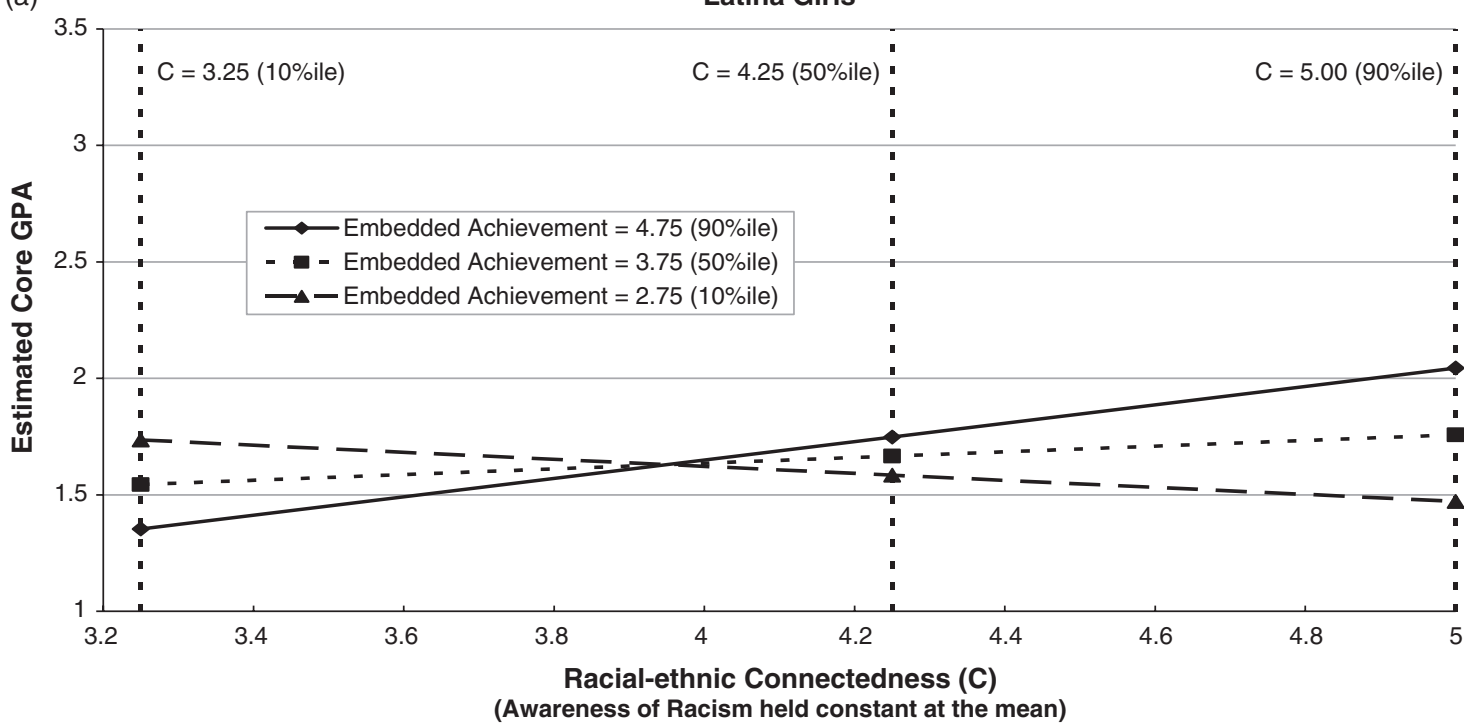

Note: Percentiles used reflect the REI distributions across all four time points and all four racial-ethnic and gender groups

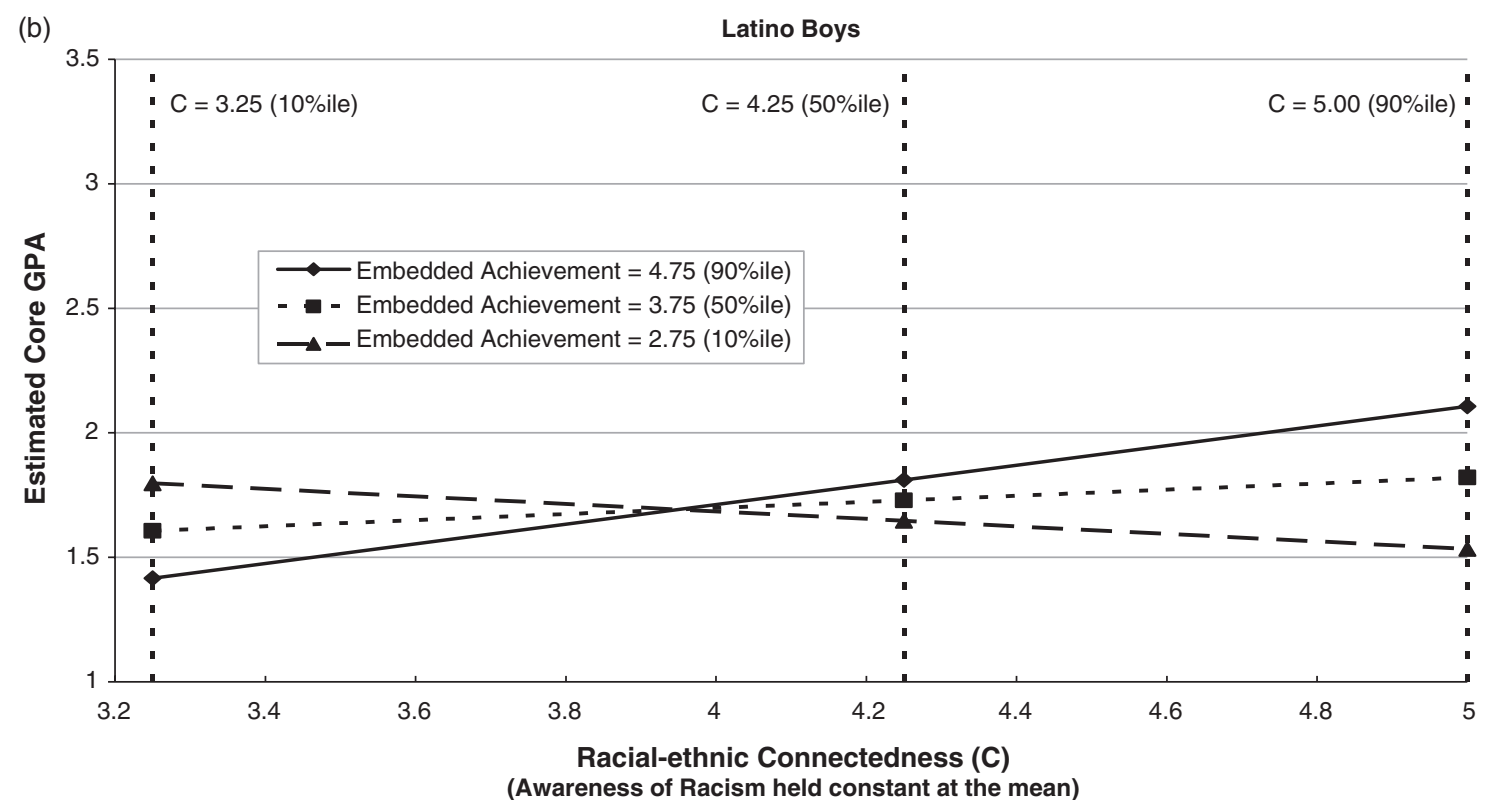

Note: Percentiles used reflect the REl distributions across all four time points and all four racial-ethnic and gender groups

Figure 2. Interactive effects of time-varying racial-ethnic identity (REI) Connectedness and Embedded Achievement on core grade point average at the beginning of eighth grade and the end of ninth grade (grades shown are for African American girls). Note. Percentiles used reflect the REI distributions across all four time points and all four racial-ethnic and gender groups.

We expected that the three components of REI would behave similarly for African American and Latino youth. With regard to gender differences, prior research suggests more risk of academic failure for boys (e.g., Orfield et al., 2004) and that impact of REI may be gendered (e.g., Oyserman et al., 1995).

We used HLM to assess change in REI over time and the time-varying association of REI and grades, a methodological improvement over previous regression-based analyses. Our results suggest that REI Connectedness, REI Awareness of Racism, and REI Embedded Achievement are relatively stable by mid-adolescence and are important predictors of grades for low-income African American and Latino youth. While we found support for the assumption that the relationship between REI and academic 

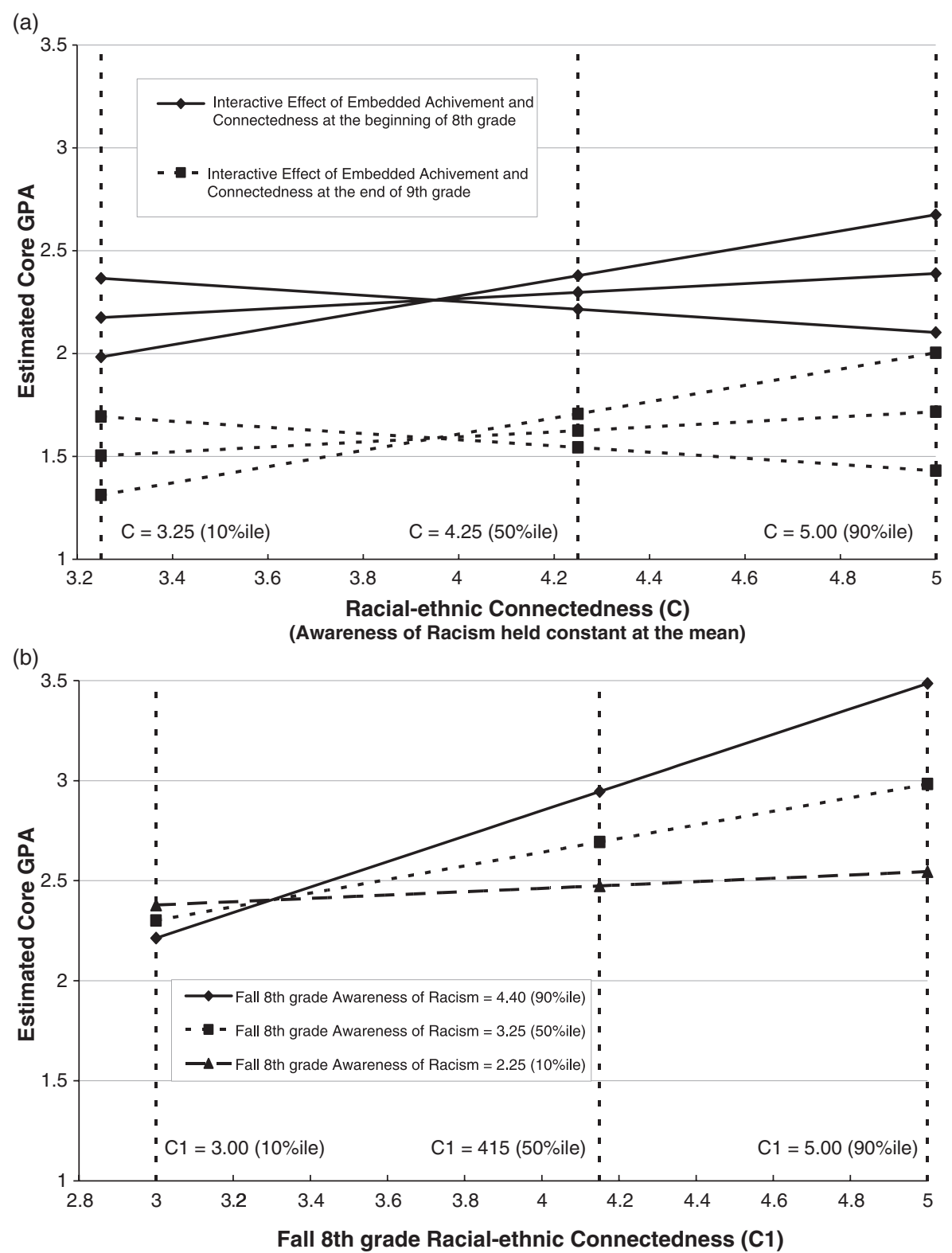

Figure 3. Interactive effects of fall eighth-grade racial-ethnic identity (REI) Connectedness and Awareness of Racism on core grade point average. Note. Percentiles used reflect the REI distributions across all four time points and all four racial-ethnic and gender groups.

achievement would not differ by race-ethnicity, the assumption that effects of REI would be gendered was not supported. In addition to the relative stability of REI over time, we also found a slight but significant upward shift in each component of REI, supporting the assertion that the transition to high school can be a "consciousness-raising" experience for minority youth who become more attuned to their REI as they move from middle schools to more heterogeneous high schools (French et al., 2000).

With regard to the relationship between REI and grades, we found that Latino and African American youth high in REI Awareness of Racism and those high in both REI Connectedness and REI Embedded Achievement attain better grades at each assessment point, results that support previous findings (Oyserman et al., 1995; Oyserman, Brickman, \& Rhodes, in press). Thus, even though over time REI increases and grades decrease, at each point in time, REI is associated with better academic achievement, suggesting that REI buffers youth from even steeper declines in grades. We also examined the ability of initial REI to predict subsequent GPA trajectories, finding that while youth high in both REI Connect- 
edness and REI Awareness of Racism at the beginning of eighth grade had higher grades across eighth and ninth grades, REI did not predict change in slope of change but rather difference in average levels.

We identified a difference in the relationship between REI and GPA at each point in time and the relationship between initial (fall eighth grade) REI and GPA across the subsequent 2 years. Specifically, while effects of REI Connectedness and Awareness of Racism are the same at each point in time and across time, the effect of REI Embedded Achievement differs. It predicts GPA at each point in time, but initial (fall eighth grade) REI Embedded Achievement does not predict GPA across subsequent years. One possibility is that this is due to larger within-student differences in REI Embedded Achievement over time. Therefore, we added withinstudent change in REI Embedded Achievement to our HLM Model 3 equation to see whether individual level of change at each point in time was a significant factor. However, model fit was not significantly improved, suggesting that within-student change in REI Embedded Achievement in and of itself was not the source of this difference.

A possible interpretation is that REI Embedded Achievement is a focus of REI identity exploration during mid-adolescence. Because doing well in school is so intimately connected with developing an adult identity, youth may be more actively re-assessing if "we" value school and schooling. It may be that it is the answer students give to this question at each point in time that influences their school effort (and grades), not previous or subsequent answers. REI Embedded Achievement may be more sensitive to shifting contextual factors than other aspects of REI. Contextual factors such as heterogeneity of high school in race-ethnicity and social-class, or neighborhood features such as racial-ethnic segregation and economic deprivation may be particularly influential in the ability of youth to sustain Embedded Achievement. The current data do not allow for empirical assessment of this possibility, although it is clearly an important focus for future research. To better understand individual predictors of change and stability in REI, we are currently examining neighborhood- and parent-context effects using a separate sample of African American youth (Oyserman, Bybee \& Dai, 2006). In these analyses, we do find gendered effects of neighborhoods on both REI Embedded Achievement and REI Connectedness.

Some researchers have posited that a path to academic success is to adopt a "raceless" identity in which race is irrelevant to self-concept (Fordham \& Ogbu, 1986). Other researchers disagree, arguing that in a racialized society, being aschematic for raceethnicity and not including racial-ethnic in identity increases vulnerability to stereotype threat effects (Oyserman, Kemmelmeier, et al., 2003). We are not able to address this issue directly in the current study because few youth (only five) could plausibly be viewed as being aschematic (e.g., very low in Connectedness and Embedded Achievement). Consequently, our results should be interpreted as focused on youth who endorse all three components of REI to varying degrees. By studying the relationship of REI to grades in time and over time, our analyses underscore the need to understand both how REI matters and what influences REI over time, taking into account both developmental and social contextual changes.

We looked for but did not find other published research that assesses and analyzes REI and its relationship with academic outcomes over multiple time points. Congruent with a social developmental approach, our results show both stability and change. Using the Oyserman tripartite model (Oyserman et al., 1995), we show that REI operationalized as Connectedness, Awareness of Racism and Embedded Achievement is a useful model for understanding REI and its association with academic outcomes whether thinking about African American or Latino mid-adolescents. Our findings are important both because they point to commonalities in how REI operates among African American and Latino youth, and because they highlight the positive influence of content of REI on academic outcomes among low-income youth. Taken together, our results provide the basis for REI-based preventive intervention in both racially-ethnically segregated and multiracial, multiethnic contexts.

\section{References}

Bernal, M., \& Knight, G. (1997). Ethnic identity of Latino children. In J. García \& M. Zea (Eds.), Psychological interventions and research with Latino populations (pp. 15-38). Newton, MA: Allyn \& Bacon.

Bernal, M., Knight, G., Garza, C., Ocampo, K., \& Cota, A. (1990). The development of ethnic identity in Mexican American children. Hispanic Journal of Behavioral Sciences, 12, 3-24.

Bigler, R., Averhart, C., \& Liben, L. (2003). Race and the workforce: Occupational status, aspirations, and stereotyping among African American children. Developmental Psychology, 39, 572-580.

Bowman, P., \& Howard, C. (1985). Race-related socialization, motivation, and academic achievement: A study of black youths in three-generation families. Journal of the American Academy of Child Psychiatry, 24, 134-141. 
Crocker, J., Luhtanen, R., Blaine, B., \& Broadnax, S. (1994). Collective self-esteem and psychological well-being among white, black, and Asian college students. Personality and Social Psychology Bulletin, 20, 503-513.

Crocker, J., \& Major, B. (1989). Social stigma and selfesteem: The self-protective properties of stigma. Psychological Review, 96, 608-630.

Croizet, J., \& Claire, T. (1998). Extending the concept of stereotype and threat to social class: The intellectual underperformance of students from low socioeconimic backgrounds. Personality and Social Psychology Bulletin, 24, 588-594.

Cross, S., \& Madson, L. (1997). Models of the self: Self-construals and gender. Psychological Bulletin, 122, 5-37.

Cross, J. E. Jr. (1991). Shades of black: Diversity in African American identity. Philadelphia: Temple University Press.

Erikson, E. H. (1968). Identity: Youth and crisis. New York: Norton \& Co.

Ferguson, R. (2001). Test-score trends along racial lines 1971 to 1996: Popular culture and community academic standards. In N. Smelser, W. Wilson, \& F. Mitchell (Eds.), America becoming: Racial trends and their consequences (pp. 348-390). Washington, DC: National Academy Press.

Fordham, S., \& Ogbu, J. U. (1986). Black students' school success: Coping with the "burden of acting White". Urban Review, 18, 176-206.

French, S., Seidman, E., Allen, L., \& Aber, J. (2000). Racial/ ethnic identity, congruence with the social context, and the transition to high school. Journal of Adolescent Research, 15, 587-602.

Graham, S. (2001). Inferences about responsibility and values: Implication for academic motivation. In F. Salili \& C. Chiu (Eds.), Student motivation: The culture and context of learning (pp. 31-59). Dordrecht, the Netherlands: Kluwer Academic Publishers.

Gutman, L. M., Sameroff, A. J., \& Eccles, J. S. (2002). The academic achievement of African American students during early adolescence: An examination of multiple risk, promotive, and protective factors. American Journal of Community Psychology, 30, 367-400.

Hudley, C., \& Graham, S. (2001). Stereotypes of achievement striving among early adolescents. Social Psychology of Education, 5, 201-224.

Kasen, S., Cohen, P., \& Brook, J. (1998). Adolescent school experiences and dropout, adolescent pregnancy, and young adult deviant behavior. Journal of Adolescent Research, 13, 49-72.

Leventhal, T., \& Brooks-Gunn, J. (2004). A randomized study of neighborhood effects on low-income children's educational outcomes. Developmental Psychology, 40, $488-507$.

Markus, H., \& Oyserman, D. (1989). Gender and thought: The role of the self-concept. In M. Crawford \& M. Gentry (Eds.), Gender and thought: Psychological perspectives (pp. 100-127). New York: Springer Verlag, New York Inc.
McDermott, P. A. (1995). Sex, race, class, and other demographics as explanations for children's ability and adjustment: A national appraisal. Journal of School Psychology, 33, 75-91.

Orfield, G., Losen, D., Wald, J., \& Swanson, C. (2004). Losing our future: How minority youth are being left behind by the Graduation rate crisis. Cambridge, MA: The Civil Rights Project at Harvard University (Contributors: Advocates for Children of New York, The Civil Society Institute, from http://www.civilrightsproject.harvard. edu).

Oyserman, D., Brickman, D., \& Rhodes, M. (in press). Racial-ethnic identity in adolescence: Content and consequences for African American and Latino youth. In A. Fuligni (Ed.), Social categories, identities and educational participation. New York: Russell-Sage.

Oyserman, D., Bybee, D., \& Dai, H. (2006). Neighborhood effects on content of racial-ethnic identity in adolescence. Under editorial review.

Oyserman, D., Bybee, D., \& Terry, K. (2003). Gendered racial identity and involvement with school. Self and Identity, 2, 307-324.

Oyserman, D., Bybee, D., \& Terry, K. (2006). Possible selves and academic outcomes: How and when possible selves impel action and what can be done about it. Journal of Personality and Social Psychology, 91, $188-204$.

Oyserman, D., Gant, L., \& Ager, J. (1995). A socially contextualized model of African American identity: Possible selves and school persistence. Journal of Personality and Social Psychology, 69, 1216-1232.

Oyserman, D., \& Harrison, K. (1998). Implications of cultural context: African American identity and possible selves. In J. K. Swim \& C. Stangor (Eds.), Prejudice: The target's perspective (pp. 281-300). San Diego, CA: Academic Press Inc.

Oyserman, D., Harrison, K., \& Bybee, D. (2001). Can racial identity be promotive of academic efficacy? International Journal of Behavioral Development, 25, $379-385$.

Oyserman, D., Kemmelmeier, M., Fryberg, S., Brosh, H., \& Hart-Johnson, T. (2003). Racial-ethnic self-schemas. Social Psychology Quarterly, 66, 333-347.

Oyserman, D., \& Sakamoto, I. (1997). Being Asian American: Identity, cultural constructs, and stereotype perception. Journal of Applied Behavioral Science, 33, $435-453$.

Phinney, J. (1996). Understanding ethnic diversity: The role of ethnic identity. American Behavioral Scientist, 40, $143-152$.

Quintana, S. (1998). Children's developmental understanding of ethnicity and race. Applied and Preventive Psychology, 7, 27-45.

Quintana, S., \& Segura-Herrera, T. (2003). Developmental transformations of self and identity in the context of oppression. Self and Identity, 2, 269-285.

Quintana, S., \& Vera, E. (1999). Mexican American children's ethnic identity, understanding of ethnic 
prejudice, and parental ethnic socialization. Hispanic Journal of Behavioral Sciences, 21, 387-404.

Raudenbush, S. W., \& Bryk, A. S. (2002). Hierarchical linear models: Applications and data analysis methods. Thousand Oaks, CA: Sage Publications.

Sandler, I., \& Chassin, L. (2002). Training of prevention researchers: Perspectives from the Arizona State University prevention research training program. Prevention and Treatment, 5.

Schafer, J., \& Graham, J. (2002). Missing data: Our view of the state of the art. Psychological Methods, 7, 147-177.

Seidman, E., Aber, J., Allen, L., \& French, S. (1996). The impact of the transition to high school on the selfesteem and perceived social context of poor urban youth. American Journal of Community Psychology, 24, 489-515.

Sellers, R., Rowley, S., Chavous, T., Shelton, J., \& Smith, M. (1997). Multidimensional inventory of black identity: A preliminary investigation of reliability and construct validity. Journal of Personality and Social Psychology, 73, $805-815$.

Shih, M., Pittinsky, T., \& Ambady, N. (1999). Stereotype susceptibility: Identity salience and shifts in quantitative performance. Psychological Science, 10, 80-83.

Steele, C. (1997). A threat in the air: How stereotypes shape intellectual identity and performance. American Psychologist, 52, 613-629.

Steele, C. (2004). A threat in the air: How stereotypes shape intellectual identity and performance. In J. A. Banks \& C. A. M. Banks (Eds.), Handbook of research on multicultural education (2nd ed., pp. 682-699). San Francisco: Jossey-Bass.

Steinitz, V. A., \& Solomon, E. R. (1986). Starting out: Class and community in the lives of working-class youth. Philadelphia: Temple University Press.

Stoep, A., Weiss, N., Kuo, E., Cheney, D., \& Cohen, P. (2003). What proportion of failure to complete secondary school in the US population is attributable to adolescent psychiatric disorder? Journal of Behavioral Health Services and Research, 30, 119-124.

Taijfel, H., \& Turner, J. C. (1986). The social identity theory of intergroup behavior. In S. Worchel \& W. Austin (Eds.), Psychology of intergroup relations (2nd ed., pp. 7-24). Chicago: Nelson-Hall.

\section{Appendix A}

1. Model 1: The full (untrimmed) linear model for GPA with race-ethnicity set to Latino and gender set to male. Intercept $\left(B_{0}\right)$ and slope $\left(B_{1}\right)$ were modeled at the individual student level taking into account race-ethnicity and gender effects. The error term $U_{0}$ represents variation between students in the intercept; $U_{1}$ represents variation between students in the slope.

Level 1 (Occasion)

$$
\mathrm{GPA}=B_{0}+B_{1} *(\mathrm{MONTH})+R .
$$

Level 2 (Individual)

$$
\begin{aligned}
B_{0}= & G_{00}+G_{01} *(\text { Latino })+G_{02} *(\text { Male }) \\
& +G_{03} *(\text { Latino } \times \text { Male })+U_{0}, \\
B_{1}= & G_{10}+G_{11} *(\text { Latino })+G_{12} *(\text { Male }) \\
& +G_{13} *(\text { Latino } \times \text { Male })+U_{1} .
\end{aligned}
$$

2. Model 2: Full (untrimmed) HLM model of the association of time-varying REI with GPA across time

Level 1 Model (Occasion)

$$
\begin{aligned}
\mathrm{GPA}= & B_{0}+B_{1} *(\mathrm{MONTH})+B_{2} *(\text { Connectedness }) \\
+ & B_{3} *(\text { Embedded Achievement }) \\
+ & B_{4} *(\text { Awareness of Racism }) \\
+ & B_{5} *(\text { Connectedness } \times \text { Embedded Achievement }) \\
+ & B_{6} *(\text { Connectedness } \times \text { Awareness of Racism }) \\
+ & B_{7} *(\text { Embedded Achievement } \\
& \times \text { Awareness of Racism }) \\
+ & B_{8} *(\text { Connectedness } \times \text { Embedded Achievement } \\
& \times \text { Awareness of Racism })+R .
\end{aligned}
$$

Level 2 Model (Individual)

$$
\begin{aligned}
B_{0}= & G_{00}+G_{01} *(\text { Latino })+G_{02} *(\text { Male }) \\
& +G_{03} *(\text { Latino } \times \text { Male })+U_{0}, \\
B_{1}= & G_{10}+G_{11} *(\text { Latino })+G_{12} *(\text { Male }) \\
& +G_{13} *(\text { Latino } \times \text { Male })+U_{1}, \\
B_{2}= & G_{20}+G_{2} 1 *(\text { Latino })+G_{22} *(\text { Male }) \\
& +G_{23} *(\text { Latino } \times \text { Male }), \\
B_{3}= & G_{30}+G_{31} *(\text { Latino })+G_{32} *(\text { Male }) \\
& +G_{33} *(\text { Latino } \times \text { Male }), \\
B_{4}= & G_{40}+G_{41} *(\text { Latino })+G_{42} *(\text { Male }) \\
& +G_{43} *(\text { Latino } \times \text { Male }), \\
B_{5}= & G_{50}+G_{51} *(\text { Latino })+G_{52} *(\text { Male }) \\
& +G_{53} *(\text { Latino } \times \text { Male }), \\
B_{6}= & G_{60}+G_{61} *(\text { Latino })+G_{62} *(\text { Male }) \\
& +G_{63} *(\text { Latino } \times \text { Male }), \\
B_{7}= & G_{70}+G_{71} *(\text { Latino })+G_{72} *(\text { Male }) \\
& +G_{73} *(\text { Latino } \times \text { Male }), \\
B_{8}= & G_{80}+G_{81} *(\text { Latino })+G_{82} *(\text { Male }) \\
& +G_{83} *(\text { Latino } \times \text { Male }) .
\end{aligned}
$$

3. Model 3: Full (untrimmed) HLM model of the effect of initial REI on GPA across time. To simplify the presentation, only the linear equations are presented here; quadratic terms were tested, but none was found to be significant.

Level 1 Model (Occasion)

$$
\text { GPA }=B_{0}+B_{1} *(\text { Month })+R .
$$


Level 2 Model (Individual)

$$
\begin{aligned}
B_{0}= & G_{00}+G_{01} *(\text { Latino })+G_{02} *(\text { Male }) \\
+ & G_{03} *(\text { Latino } \times \text { Male }) \\
& +G_{04} *(T 1 \text { Connectedness }) \\
& +G_{05} *(T 1 \text { Awareness of Racism }) \\
+ & G_{06} *(T 1 \text { Embedded Achievement }) \\
+ & G_{07} *(T 1 \text { Connectedness } \\
& \times T 1 \text { Awareness of Racism }) \\
+ & G_{08} *(T 1 \text { Connectedness } \\
& \times T 1 \text { Embedded Achievement }) \\
+ & G_{09} *(T 1 \text { Embedded Achievement } \\
& \times T 1 \text { Awareness of Racism }) \\
+ & G_{10} *(T 1 \text { Connectedness } \\
& \times T 1 \text { Awareness of Racism } \\
& \times T 1 \text { Embedded Achievement })+U_{0},
\end{aligned}
$$

$$
\begin{aligned}
B 1= & G_{10}+G_{11} *(\text { Latino })+G_{12} *(\text { Male }) \\
& +G_{13} *(\text { Latino } \times \text { Male }) \\
& +G_{14} *(T 1 \text { Connectedness }) \\
& +G_{15} *(T 1 \text { Awareness of Racism }) \\
+ & G_{16} *(T 1 \text { Embedded Achievement }) \\
+ & G_{17} *(T 1 \text { Connectedness } \\
& \times T 1 \text { Awareness of Racism }) \\
+ & G_{18} *(T 1 \text { Connectedness } \\
& \times T 1 \text { Embedded Achievement }) \\
+ & G_{19} *(T 1 \text { Embedded Achievement } \\
& \times T 1 \text { Awareness of Racism }) \\
+ & G_{110} *(T 1 \text { Connectedness } \\
& \times T 1 \text { Awareness of Racism } \\
& \times T 1 \text { Embedded Achievement })+U_{1} .
\end{aligned}
$$

Note: $T 1=$ fall eighth grade. 